\title{
Correction to: Aerodynamics and the role of the earth's electric field in the spiders' ballooning flight
}

\author{
Moonsung $\mathrm{Cho}^{1,2}$ (D)
}

Published online: 30 March 2021

c) Springer-Verlag GmbH Germany, part of Springer Nature 2021

Correction to: Journal of Comparative Physiology A https://doi.org/10.1007/s00359-021-01474-6

Authors would like to correct the error in their publication. The Word Equations are transferred incorrectly in the original article and now got corrected in the original version.

The original article has been corrected.

Publisher's Note Springer Nature remains neutral with regard to jurisdictional claims in published maps and institutional affiliations.

The original article can be found online at https://doi.org/10.1007/ s00359-021-01474-6.

Moonsung Cho

mscho@kau.ac.kr

1 Animal Physiology, University of Rostock,

Albert-Einstein-Str. 3, 18059 Rostock, Germany

2 School of Aeronautical and Mechanical Engineering,

Korea Aerospace University, 76 Hanggongdaehang-ro,

Goyang-si 10540, Republic of Korea 